\title{
How does internal migration affect the emotional health of elderly parents left-behind?
}

\author{
Juliane Scheffel $^{1}$ iD . Yiwei Zhang ${ }^{2}$
}

Received: 5 February 2016 / Accepted: 26 June 2018 / Published online: 13 July 2018 (C) The Author(s) 2018

\begin{abstract}
The ageing population resulting from the one-child policy and massive flows of internal migration in China pose major challenges to elderly care in rural areas where elderly support is based on a traditional inter-generational family support mechanism. We use data from the China Health and Retirement Longitudinal Study to examine how migration of an adult child affects the emotional health of elderly parents left-behind. We identify the effects using fixed effects and IV approaches which rely on different sources of variation. We find that migration reduces happiness by 6.6 percentage points and leads to a 3.3 percentage points higher probability of loneliness. CES-D scores of elderly parents are severely increased pushing average scores close to the cut-off indicating clinical levels of depressive symptoms. As emotional health is a key determinant of the overall health status, our findings have significant impacts on economic development in China.
\end{abstract}

Keywords Internal migration $\cdot$ China $\cdot$ Mental health $\cdot$ Elderly parents · Left-behind

JEL Classification $\mathrm{I} 15 \cdot \mathrm{J} 14 \cdot \mathrm{O} 15 \cdot \mathrm{R} 23$

Responsible editor: Klaus F. Zimmermann

Juliane Scheffel

j.scheffel@leeds.ac.uk

1 Division of Economics, Leeds University Business School, Maurice Keyworth Building, Leeds, LS2 9JT, UK

2 Beijing, China 


\section{Introduction}

Primary social, economic and cultural reforms since 1978 have resulted in an accelerated development of the Chinese economy. Rapid economic growth combined with urban-prioritised and pro-coastal policies caused a great demand for cheap labour. Meanwhile, the increasing efficiency level of agriculture production due to the practice of the Household Responsibility System launched in the early 1980s has led to a large labour surplus in rural China. ${ }^{1}$ As a result, the migrant population has increased more than threefold from 70 million in 1993 to 274 million in 2014, and the number keeps rising (National Bureau of Statistics of China 2014).

As a result of primarily younger individuals (aged between 18 and 29 years) leaving their homes in search of better employment opportunities elsewhere as well as an increasing life expectancy and rapidly declining fertility rates, ${ }^{2}$ China and in particular its rural areas is facing a dramatic ageing problem. Jackson and Howe (2004) predict that the elderly population above 60 years of age will reach $28 \%$ of the total Chinese population in 2040, more than twice the amount of 2012.

This demographic transition is causing considerable pressure on the family. In China, old age support is traditionally the role of adult children (Chyi and Mao 2012). More precisely, according to Confucian filial piety, it is the role of the eldest son and his family to care for parents in old age. In addition, the current pension system is under-developed such that elderly parents rely heavily on their families as main source of financial support in old age. With the drastically increasing migration flows over the past decades, this informal safety net is however dramatically weakening leaving elderly parents more and more often in precarious situations. Employment and income of migrating children in the host communities are far from being secure. Migrants often work in informal or precarious employment and have risky incomes excluding them from social security payments (Knight and Yueh 2004; Giles et al. 2010; Biao 2007). As a consequence, financial support from a migrant child may be unreliable putting the elderly at a greater risk of falling into poverty (Giles et al. 2010). This may significantly exacerbate an elderly parent's vulnerability leading to significant distress and emotional ill-health. Meanwhile, it is inherently more difficult for migrant adult children to provide emotional and physical support to their parents while working elsewhere, which may further severely impair parental emotional wellbeing. In this paper, we assess how migration of an adult child affects the emotional health of elderly parents. For this purpose, we use data from the China Health

\footnotetext{
${ }^{1}$ The Household Responsibility System (or Contract Responsibility System) is an agricultural system that was implemented in the early 1980s. Peasant households were given access to farmland from the village authority, which was allocated primarily by household size. This system returns some freedom back to farmers and allows the household head to be responsible for their profits and losses, empowers peasants to grow crops freely and allows them to trade their agricultural products in a relatively competitive market at an unregulated price. The implementation of this system has increased the initiative and motivation of farmers and the efficiency of the production and has contributed to generating a labour surplus in rural areas (Zweig 1997).

${ }^{2}$ The implementation of the One-Child Policy has led to historically low fertility rates - 1.64 in 2011 , compared to 4.36 in 1963 (National Bureau of Statistics of China 2012).
} 
and Retirement Longitudinal Study (CHARLS) for 2011 and 2013 which is particularly well suited for this study as it contains detailed information of both elderly parents and all of their children.

Due to the increasing longevity and ageing populations across developed and middle-income countries, a growing body of literature has emerged examining various aspects of the impact of migration on families left-behind. Health-related outcomes have received considerable attention. The basic idea is that in these countries remittances of migrants to their families left-behind may allow the elderly to have access to better medical care which may positively affect their health (Vanwey 2004; Amuedo-Dorantes and Pozo 2011; Ao et al. 2016). Yet, much in contrast to these countries, remittances in China have not contributed to a substantial development of rural areas and have had only limited impact on the welfare of the left-behind (Biao 2007) for much of the income of migrants remains in urban areas. Consequently, only limited positive health effects, if any, can be expected of remittances from migrant children. Moreover, Li and Démurger (2013) argue that migration reduces the number of labourers on family farms. As a consequence, elderly parents often have to continue to work on their farms to replace the missing child (Pang and de Brauw 2004) which might significantly harm the elderly's physical health. Migration does not only reduce the number of labourers, it also inherently reduces the number of caregivers and hence the quality of care received by the elderly. As a consequence, health conditions are likely to be exacerbated (Davin 1999; Croll 1997). A priori, health effects resulting from migration are unclear and remain an empirical question. Considerably lower health outcomes among the elderly resulting from migration of an adult child are found for Mexico (Antman 2010, 2016) and China (Huang et al. 2015; Ao et al. 2016). In contrast, Kuhn et al. (2011) find for Indonesia that migration of an adult child does not worsen an elderly parent's health. On the contrary, it seems to have improved it. Similar positive health outcomes are found for Bangladesh (Kuhn 2004), Moldova (Böhme et al. 2015) and Tonga (Gibson et al. 2011).

It is arguable whether over a short period of time adverse effects on physical health are indeed the result of migration of an adult child because any changes in physical health may take time to take effect. Even with careful identification strategies, it is more plausible that migration of a child first affects an elderly parent's emotional health rather than causing an immediate deterioration of physical health. Evidence in the medical literature shows that mentally healthier people are more inclined to live in a healthy way (Veenhoven 2008) and also people with positive mental states are found to have better immune responses (Cohen et al. 1995) and are hence healthier on average.

A growing body of literature has devoted attention to assessing the effects of migration on parental emotional health. Reduced co-residency in extended households may result in loneliness and feelings of powerlessness (Yao 2011; Zhang and Li 2004; Zhang et al. 2005) but it is also found to reduce happiness among the elderly (Chyi and Mao 2012). Migration may also improve the elderly's psychological wellbeing as it tends to indicate better innate ability of a migrant child, which parents can be proud of (Zhuo and Liang 2006). Moreover, migration inherently reduces the possibility of quarrels between family members which could mitigate some of the adverse effects on emotional health (Zuo and Li 2011). Antman (2016) investigates 
emotional health outcomes as one of many health outcomes resulting from migration in Mexico. She finds that migration leads to worsened levels of emotional wellbeing. For Ireland, Mosca and Barrett (2016) find that it is particularly mothers whose emotional health deteriorates if a child migrates.

Our main challenge is to address the endogeneity of migration. To do so, we adopt two different estimation strategies. First, an important source of endogeneity is the possible selection of migrants and their families in terms of physical and emotional health. In this context, the so-called healthy migrant effect states that migrants tend to be healthier compared to randomly selected non-migrants (Jasso et al. 2004; Giles and $\mathrm{Mu}$ 2007; Rubalcava et al. 2008; Riosmena et al. 2012; Farré 2015). As emotional wellbeing is an important determinant of a person's physical health (Clark and Oswald 2002; Easterlin 2004; Galper et al. 2006), we expect migrants to also be positively selected in this regard. Moreover, if healthier parents have healthier children, we believe that parents of migrant children are emotionally healthier on average. Not accounting for this selectivity may understate the negative effects of migration on parental emotional health. To eliminate such time-invariant sources of individual heterogeneity, we exploit the panel structure of the CHARLS data. More specifically, we use a fixed effects approach to allow for individual differences over time to identify how changes in the migration decision of an adult child affect changes in emotional health of the elderly parent.

To strengthen the identification strategy, we additionally adopt an instrumental variable approach. This is helpful to account for reverse causality which occurs if children take their migration decision in response to their parents' overall emotional health status. Giles and $\mathrm{Mu}$ (2007) find that poor parental health in China significantly reduces the migration probability of adult children. For this approach, we exploit variations in community characteristics that might influence the child's migration decision but are not related directly to parental emotional health. As instruments, we use (i) the percentage of a community's migrant population relative to its total population and (ii) a community's per capita total revenues in 2010 . We make use of the fact that a child is more likely to seek employment opportunities elsewhere if the share of migrants within a community is higher which lowers migration costs (Rozelle et al. 1999; Mckenzie and Rapoport 2007; Fan 2008) or if the home community's economic condition is relatively worse.

Our main identification strategy regarding parental emotional wellbeing relies on short-run changes in the migration status of an adult child. The reduced support network resulting from the absence of an adult child may cause severe feelings of unhappiness and loneliness and may eventually lead to more pronounced depressive symptoms. Such deteriorated emotional health outcomes may further impair the elderly's physical health and might hence be crucial risk factors to the overall health status. Our findings suggest that parents with migrant children have significantly worse emotional health outcomes and have severely increased probabilities to suffer from clinical depression. Return migration can mitigate to some extent the adverse effects on mental wellbeing.

The remainder of this paper proceeds as follows. In the next section, we will provide a brief overview of the institutional background in China. In Section 3, we will briefly introduce the data and present descriptive statistics. Section 4 will detail the 
empirical strategy. Our main results are presented in Section 5. In the subsequent section, we examine different definitions of the migration status. For example, we divide the sample of migrants into returning and newly migrating children to examine the resulting differential effects. Finally, Section 7 concludes the paper.

\section{Institutional background}

The current Chinese social security system provides different social safety nets for urban and rural areas (Wang 2005). While approximately $45.4 \%$ of urban elderly rely on retirement pension funds over the age of 60 (Giles et al. 2011), merely $4.6 \%$ of the elderly in rural areas receive pension incomes according to the 2005 one percent population sample. This dichotomy has historical origins in that land was regarded as main form of insurance for old age in rural areas since it can be passed on from parents to their children. The land arrangement laws allow young migrants to rent out their land to others so that their parents are not obliged to continue farming. Participation in pension funds in rural areas is voluntary and benefits are far low. Data from Du (2003) suggest that only $19.61 \%$ of the elderly in rural China were eligible to obtain a pension which provided a yearly pension of $660 \mathrm{RMB}^{3}$ This is below the poverty line (Giles et al. 2010).

Resulting from a lack of formal pension, elderly parents in rural areas rely heavily on their families as main source of support in old age (Giles et al. 2010). In urban areas, workers in the informal sector are not eligible for pensions in old age and include employment in casual or temporary work, self-employment and unpaid work in family enterprises, as well as migrant workers (Giles et al. 2011). These employment forms are common in China, in particular among older workers which means that these people depend heavily on their families in old age. In addition, traditional beliefs are based on Confucian "filial pity" according to which adult children are responsible for the support of their elderly parents even if they receive financial support in the form of old age pensions. More specifically, the main responsibility rests with the oldest son and his family. However, with improved economic development and modernization, there is an increasing concern that these traditional norms have weakened leading to a deterioration of the willingness and ability of the younger generation to support the elderly (Chen and Silverstein 2000).

The reduction in the number of caregivers as a result of migration strongly weakens the informal security safety net. This is particularly concerning in rural areas and calls for an urgent extension of the coverage of the formal security system to rural areas. The new rural pension system, ${ }^{4}$ as proposed by the state council, aims to cover all rural regions by 2016, the end of 12th five-year plan. However, it faces obstacles such as a severe funding gap and empty pension accounts (Wang 2005).

\footnotetext{
${ }^{3}$ Six hundred sixty RMB correspond to slightly more than $100 \$$. Pensions vary among different regions. In some rich coastal provinces such as Zhejiang Province, the basic pension amounts to 960 RMB per year. ${ }^{4}$ Unlike the old rural pension system, which emphasizes peasants' self-insurance via savings, the new rural pension system uses government fiscal revenue to provide subsidies.
} 


\section{Data and descriptive statistics}

\subsection{Data and variables}

The data used in this study is taken from the China Health and Retirement Longitudinal Study (CHARLS), which is a joint effort of Peking University in China, the Behavioural and Social Research Division of the National Institute on Ageing and the World Bank. Mid-aged and elderly people aged 45 years or above are surveyed. The dataset is designed for an easy comparison with the Health and Retirement Study (HRS) and other international ageing surveys such as the English Longitudinal Study of Aging (ELSA) and the Survey of Health, Aging and Retirement in Europe (SHARE). Based on the experience of the pilot survey in Gansu and Zhejiang Provinces in 2008, the survey probes 28 provinces in China since 2011 and follows the same individuals every two years. It covers around 450 villages/communities within 150 counties/districts. The data also contains detailed information for a random sample of people aged 45 years or older and all of their household members. ${ }^{5}$ If more than one family is living together as one household, one of them with ageeligible members will be randomly chosen by the survey team. In case that there is only one household member who satisfies that age criterion, he or she is defined as the main respondent. If there are more than one age-eligible members, one of them is randomly selected as main survey respondent. Regardless of age, the spouse of the main respondent is automatically surveyed as well.

For our study, we use the nation-wide data for 2011 and 2013. One of the many appealing features of this dataset, the one that makes it particularly well suited for our analysis, is that it provides not only rich information about the elderly household head and spouse but also a vast array of information for all cohabiting and non-cohabiting children. In this study, we focus on respondents aged 60 or above. Since the main purpose of migration is to seek better work opportunities (Lee and Xiao 1998; Chen 1998; Sun 2002), we further restrict the sample to working age children above the age of 16 years. This finally leaves us with 6189 observations with non-missing values.

We define an adult child as migrant if he or she lives in another county, or further away from their parents. ${ }^{6}$ Children who moved abroad are also defined as migrants. ${ }^{7}$ As main variable of interest, we construct a dummy which takes the value of 1 if at least one of the adult children of an elderly person has migrated to another county or abroad. We observe that $48.7 \%$ of our sample households have at least one migrant child. Among all children, we find that 23.0 and $23.8 \%$ have migrated in 2011 and 2013, respectively.

Emotional health indicators are obtained from a variety of questions regarding an elderly's feelings of happiness, loneliness or depression in the week prior to the

\footnotetext{
${ }^{5}$ Under the Chinese particular residency registration system—-the hukou system—a household usually consists of a pair of parents and their child(ren). The father or the oldest son of a family is usually registered as "the head of household".

${ }^{6}$ The Chinese provinces and autonomous regions are divided into autonomous prefectures, counties, autonomous counties and cities.

${ }^{7}$ Our sample contains 12 adult children who moved abroad: 4 in 2011 and 8 in 2013.
} 
interview. Survey responses to these questions are defined on a scale ranging from 1 to 4: (1) rarely or none of the time ( $<1$ day); (2) some or a little of the time (1-2 days); (3) occasionally or a moderate amount of the time (3-4 days); (4) most or all of the time (5-7 days). In our main analysis, we classify an elderly person as happy, depressed or lonely if he or she has experienced these feelings occasionally (3-4 days) or more during the past week.

Happiness is our broadest indicator of emotional health. It refers to the general level of life satisfaction (Frey and Stutzer 2002; Clark and Oswald 2002) and is likely to be volatile and to strongly depend on daily incidents or life events. Loneliness relates to companionship, i.e. the feeling of affiliation generated by the family, other relatives or the community. We think of these indicators as describing short-term emotions which may change relatively quickly. In contrast, feeling depressed may describe a more clinical level of mental ill-health which rather originates from genetic variations, nurture, environment or certain chemical influences (e.g. side effects of drugs), etc. We therefore regard it as a longer-term emotional outcome.

Emotions experienced in the past week may not be representative of the elderly parent's general emotional wellbeing. To account for a more general definition of emotional health, we employ an alternative measure for depressive symptoms. People with systematically poor emotional health may feel sad and depressed over an extended period of time. Depressive disorders are accompanied by problems sleeping, a lack of appetite etc. (Radloff 1977). The CHARLS data provides 10 questions regarding an elderly's experience of depressive symptoms during the week prior to the survey. These questions correspond to the 10-item depression scale provided by the Center for Epidemiological Studies. We therefore construct an alternative indicator of depressive symptoms which is based on responses to these questions which are provided on the same 4-item scale as described before. We follow Radloff (1977) and code responses from 0 (rarely) to 3 (most of the time) for negatively phrased questions such as "I felt depressed". For positively phrased questions such as "I felt hopeful about the future", we reverse the scoring to range from 0 (most of the time) to 3 (rarely). By adding up the responses to all of these 10 questions, we derive the socalled CES-D indicator which ranges from 0 to a maximum of 30 with larger scores reflecting more pronounced depressive symptoms. Cronbach's $\alpha$ is 0.780 which suggests an acceptable level of internal consistency of the indicator items. ${ }^{8}$ Figure 1 illustrates the distribution of the CES-D score by household migration status. The distributions are relatively similar for both groups. The one for elderly parents in migrant households is slightly shifted to the right and has slightly fatter tails at higher CES-D scores, which suggests higher average CES-D scores for this group.

We control for a rich set of control variables for both parents and their adult children. To allow for a non-linear impact of the parent's age, we use two age dummies, one for parents aged between 70 and 80 and one for parents above 80 years of age to account for life cycle effects. Younger parents (below 70) are defined as control

\footnotetext{
${ }^{8}$ Our level of internal consistency is slightly below than that of Lei et al. (2014) who find a Cronbach's $\alpha$ of 0.815 for a larger sample of Chinese elderly for the 2011 wave of the CHARLS data.
} 


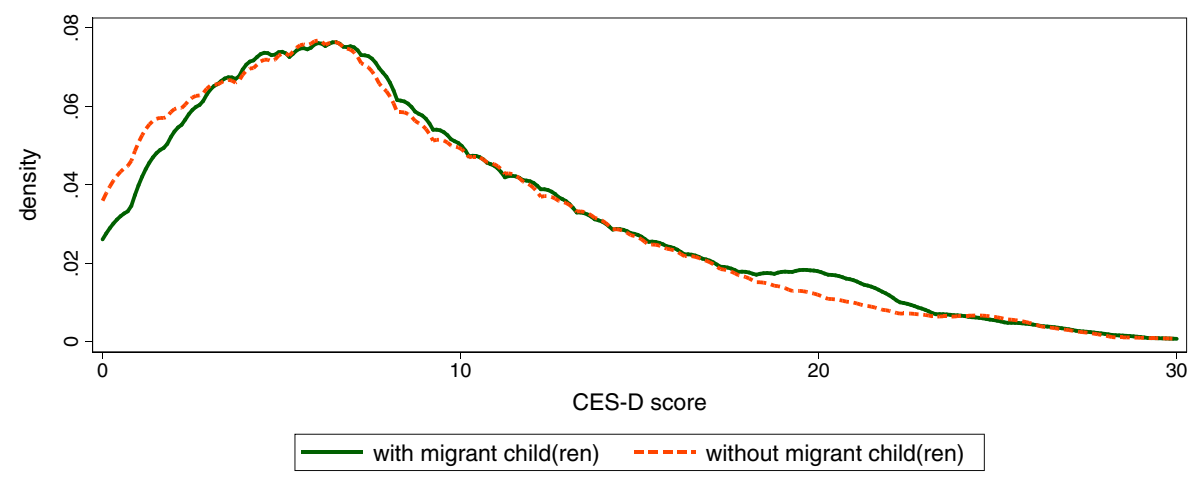

Fig. 1 The distribution of CES-D scores by the household's migration status

group. We further account for the parent's gender and the number of children and we include a dummy for being widowed, all of which are likely to differentially affect emotional health. As education among Chinese elderly does not vary much, we only control for illiteracy and educational levels above high school to allow for a correlation between human capital differences and emotional health (Case and Paxson 2008; Cheng et al. 2002). As emotional health is affected by physical health, we define two indicators for difficulties with basic "activities of daily life" (ADLs such as bathing, dressing or undressing, getting in or out of bed, going to the toilet and eating) and "instrumental activities of daily living" (IADLs such as cooking meals, going shopping, taking phone calls, taking meds, doing housework or managing money). Each of these indicator takes the value of 1 if the elderly respondent reported to have some difficulties in performing at least one of the activities.

Additionally, we control for characteristics of an elderly's adult children and include age, marital status and the education level as measured by indicators for being illiterate and having attained a high school diploma or above. We further use the gender of the child and an indicator for being the oldest son to account for traditions and social norms that require sons and more precisely the eldest son and his family to support parents in old age (Chen and Silverstein 2000; Cong and Silverstein 2008). Daughters, in contrast, are traditionally expected to provide emotional support even if they moved into the husband's household (Silverstein et al. 2006).

\subsection{Descriptive statistics}

Average descriptive statistics of elderly respondents and their children are presented in the first column of Table 1 . The average age is 69 , education is generally low among the elderly with $31 . \%$ of our respondents being illiterate and only $5.3 \%$ having a high school degree or above. The elderly in our sample have on average 3.7 children.

The table also reports descriptive statistics by the household's migration status where the column labelled "migrants" refers to households with at least one migrant adult child. It shows that elderly parents in migrant households have more children, 
Table 1 Descriptive statistics of elderly parents by migration status of the adult child

\begin{tabular}{|c|c|c|c|c|c|c|c|}
\hline & \multicolumn{2}{|l|}{ All } & \multicolumn{2}{|c|}{ No migrants } & \multicolumn{2}{|c|}{ Migrants } & \multirow{2}{*}{$\begin{array}{l}t \text { test } \\
p \text { value }\end{array}$} \\
\hline & Mean & SD & Mean & $\mathrm{SD}$ & Mean & $\mathrm{SD}$ & \\
\hline \multicolumn{8}{|l|}{ Household characteristics } \\
\hline At least one migrant child & 0.487 & 0.500 & 0.000 & 0.000 & 1.000 & 0.000 & - \\
\hline No. of children & 3.726 & 1.579 & 3.507 & 1.512 & 3.957 & 1.616 & 0.000 \\
\hline Agricultural hukou & 0.844 & 0.363 & 0.843 & 0.364 & 0.846 & 0.361 & 0.740 \\
\hline Annual household income & 3840 & 9355 & 4149 & 9544 & 3515 & 9142 & 0.008 \\
\hline \multicolumn{8}{|l|}{ Parental characteristics } \\
\hline Age & 68.972 & 6.703 & 68.888 & 6.559 & 69.061 & 6.851 & 0.308 \\
\hline Male & 0.581 & 0.493 & 0.542 & 0.498 & 0.623 & 0.485 & 0.000 \\
\hline Illiterate & 0.317 & 0.465 & 0.336 & 0.472 & 0.297 & 0.457 & 0.001 \\
\hline More than high school & 0.053 & 0.224 & 0.061 & 0.240 & 0.044 & 0.205 & 0.002 \\
\hline Widowed & 0.297 & 0.457 & 0.327 & 0.469 & 0.265 & 0.441 & 0.000 \\
\hline ADL difficulty & 0.082 & 0.274 & 0.080 & 0.271 & 0.084 & 0.278 & 0.504 \\
\hline IADL difficulty & 0.166 & 0.372 & 0.175 & 0.380 & 0.156 & 0.363 & 0.038 \\
\hline Health status & 4.070 & 0.910 & 4.049 & 0.901 & 4.091 & 0.920 & 0.069 \\
\hline \multicolumn{8}{|c|}{ Characteristics of adult children } \\
\hline Age & 41.277 & 7.119 & 41.376 & 7.056 & 41.173 & 7.185 & 0.263 \\
\hline Male & 0.504 & 0.500 & 0.505 & 0.500 & 0.503 & 0.500 & 0.932 \\
\hline Illiterate & 0.080 & 0.271 & 0.086 & 0.281 & 0.074 & 0.261 & 0.069 \\
\hline More than high school & 0.094 & 0.291 & 0.074 & 0.262 & 0.114 & 0.318 & 0.000 \\
\hline Married & 0.944 & 0.230 & 0.957 & 0.203 & 0.931 & 0.254 & 0.000 \\
\hline \multicolumn{8}{|l|}{ Outcome variables } \\
\hline Happy & 0.587 & 0.492 & 0.589 & 0.492 & 0.586 & 0.493 & 0.803 \\
\hline Lonely & 0.205 & 0.403 & 0.197 & 0.398 & 0.213 & 0.409 & 0.119 \\
\hline Depressed & 0.310 & 0.463 & 0.298 & 0.457 & 0.323 & 0.468 & 0.035 \\
\hline CES-D & 8.907 & 6.123 & 8.690 & 6.090 & 9.137 & 6.151 & 0.004 \\
\hline$N$ & 6198 & & 3181 & & 3017 & & \\
\hline
\end{tabular}

The test of difference is based on two-tailed $t$ tests of mean differences

they tend to be more likely to be male but also to be less illiterate or widowed and to have lower annual aggregate household incomes. ${ }^{9}$ Moreover, we do not find significant differences in limitations with ADLs depending on the migration status of the adult children but IADL limitations are reduced in migrant households.

Child characteristics indicate that adult children are on average 41.3 years old. The vast majority is married and half of all adult children are men. Illiteracy rates

\footnotetext{
${ }^{9}$ All financial variables are expressed in 2010 values using the national consumer price index.
} 
are significantly lower compared to the elderly generation and $9.4 \%$ have obtained at least a high school degree. Adult children in migrant households tend to have higher levels of education on average but are less likely to be married compared to children in households without a migrant.

Finally, Table 1 also shows descriptive statistics for our main outcome variables. About $59 \%$ of the elderly report to be happy, $21 \%$ have been lonely and $31 \%$ indicate that they have felt depressed during the past week. The mean CES-D score is 8.91. Scores with values of 10 and above indicate clinically depressive symptoms using the 10-item scale. In our sample, about $39 \%$ of the elderly have CES-D scores of 10 or above, $29 \%$ of men and $53 \%$ of women. ${ }^{10}$ Moreover, the table shows negative associations between the migration status of the adult child(ren) and parental emotional health outcomes. Elderly parents with migrant children report significantly higher levels of depressive symptoms and they tend to feel slightly lonelier. These differences in outcomes could be explained in parts by differences in the sample composition between the two groups.

\section{Estimation strategy}

Our estimation strategy focuses on evaluating the impact of an adult child's migration status on the emotional health of the elderly parent $i$. Our main challenge is the endogeneity of the migration indicator. To purge its effect, we use two estimation approaches. We identify the effect based on (i) a fixed effects specification and (ii) an instrumental variable approach. These strategies will be described in more detail below.

In a first approach, we address the endogeneity of the migration indicator caused by unobserved individual characteristics that affect both the adult child's migration decision and the parent's emotional health. To overcome this source of endogeneity, we exploit the panel structure of the CHARLS data and estimate the following fixed effects model:

$$
\text { Wellbeing }_{i t}=\beta_{0}+\gamma_{1} M C_{i t}+\mathbf{P}_{i t} \beta_{1}+\mathbf{C}_{i t} \beta_{2}+\phi_{i}+\epsilon_{i t},
$$

where Wellbeing ${ }_{i t}$ refers to the emotional health indicators as described above for the elderly parent $i$ in year $t$. Our main variable of interest is $M C_{i t}$ which is a dummy variable that takes the value 1 if at least one of the adult children has migrated. The vector $\mathbf{P}_{i t}$ is a vector of parental characteristics and $\mathbf{C}_{i t}$ accounts for a number of child characteristics that potentially influence parental outcomes, $\phi_{i}$ captures an unobserved time-invariant individual-specific term and $\epsilon_{i t}$ is a random error term.

In recent years, a considerable amount of research has focussed on the "healthy migrant effect" according to which migrants tend to be healthier as compared to randomly selected non-migrants (Jasso et al. 2004; Giles and Mu 2007; Rubalcava et al. 2008; Riosmena et al. 2012; Farré 2015). The above described sources of individual

\footnotetext{
${ }^{10}$ Lei et al. (2014) provide a detailed analysis of the determinants of CES-D scores for Chinese aged 45 and above based on the 2011 CHARLS survey and find similar values.
} 
time-invariant fixed effects can occur if healthy people are more likely to have healthier children and if healthier children have a greater probability to migrate. As a person's health is positively related with emotional health (Clark and Oswald 2002; Easterlin 2004; Galper et al. 2006), we further expect the wellbeing of elderly parents in migrant households to be better on average. This form of selectivity of the migrant sample may potentially understate the negative effects of migration on parental emotional health. This means that OLS estimates are likely to be biased towards zero.

Fixed effects models can deal with this type of selection of elderly parents in migrant households and therefore allow us to identify the effect of migration of the adult child on parental emotional health. By exploiting differences in individual responses over time, we can identify how changes in the child's migration status and other major events in an elderly parent's life affect emotional wellbeing. This approach eliminates any time-invariant unobservable individual-specific characteristics, denoted as $\phi_{i}$ in Eq. 1, that are potentially correlated with both the adult child's migration decision and the elderly parent's emotional health. Fixed effects regression cannot eliminate unobserved individual-specific effects that vary over time such as shocks to the family or the elderly individual that affect both the migration decision of the adult child and parental emotional health.

As found by Giles and Mu (2007), poor parental health in China significantly reduces the migration probability of adult children. Fixed effects regressions cannot deal with endogeneity caused by reverse causality or simultaneity for the case that children take the migration decision responding to their parent's overall health. To strengthen identification and to address these sources of endogeneity, we additionally employ an instrumental variable approach. Ideally, we would want to estimate an FE-IV model to address reverse causality and the selectivity of the migrant sample at once. This however requires suitable instrumental variables that vary over time. Unfortunately, the community data we use to construct our instruments are available only for the first survey wave. As we are unable to compute changes in community level variables over time, we resort to estimating an IV approach which exploits variations in community characteristics rather than individual changes that might influence the child's migration decision but are not related directly to parental emotional health. For this purpose, we use two instrumental variables in this paper which are (i) the ratio of the community's population who live somewhere else relative to the total population in 2010 and (ii) a community's per capita agricultural and industrial revenues in 2010 .

Relevant instruments must be highly correlated with the child's migration status but not with the error term. To be valid, the instruments must, apart from their impact through the endogenous variable, not be directly correlated with parental emotional health. Our first instrument - the community share of migrants-is well established in the migration literature as proxy for the migrant network (Rozelle et al. 1999; Mckenzie and Rapoport 2007; Fan 2008). Its rationale is that active migrant networks can provide information to future migrants about job search and living arrangements in the destination regions. This reduces the costs of migrating and hence increases the migration probability. To strengthen the validity of this instrument, Table 7 in the Appendix shows community-level descriptive statistics depending on the strength of 
the migrant network. In this regard, we define a community to have a strong migrant network if its migrant share is higher than the average share among all communities. The table indicates that the communities are generally very similar. Communities with stronger migrant networks tend to have fewer paved roads but are similar in all other aspects including the availability of elderly care or activity centres. This is reassuring.

Our second instrumental variable - a community's per capita agricultural and industrial revenues in 2010 - uses the community's per capita agricultural and industrial revenues as provided by the 2011 community survey. ${ }^{11}$ The rationale of using community variations in per capita revenues is to proxy its economic conditions and can hence be viewed as a proxy for a community's job opportunities. One of the main driving forces behind a person's decision to migrate is to seek better job opportunities elsewhere to be able to afford a higher standard of living for themselves and their parents remaining behind (see for example Pang et al. 2004; Giles andMu 2007; Fan 2008; Knight and Gunatilaka 2018). If the economic outlook in the home community is better which means that per capita revenues are larger, the expected returns from migration are lower and migration becomes less attractive. Moreover, migrants face discrimination in cities in terms of employment prospects (Knight and Yueh 2004; Liu 2005; Knight and Gunatilaka 2010, 2018). They often work in informal employment and have risky incomes and they are excluded from having access to social security (Knight and Yueh 2004; Giles et al. 2010; Biao 2007). Consequently, we expect the probability to migrate to be negatively correlated with better economic conditions in the home community.

A concern which would invalidate this instrument as noted by Stevens et al. (2015) is that local mortality rates are found to be associated with a community's cyclical fluctuations in economic activity resulting from cyclical variations in the local quality of care services. In China, this is less of a concern. The concept of elderly care is still under construction and local governments rarely provide financial support (Zheng and Huang 2014). For both the provision of public services and commercial insurance, no specific funding is allocated for long-term elderly care (Zhang and $\mathrm{Hu}$ 2014). Hence, the provision of elderly care facilities or nursing homes is highly under-developed and under-funded and the quality of such services if they exist at all is very low - in particular in rural areas (Liu 2013). Although some regions have plans to develop nursing homes and elderly caring centres, the implementation is difficult. After all, the main responsibility including the financial support of elderly care lies within the family according to Confucian beliefs (Zhang and $\mathrm{Hu} 2014$; Zhang and Li 2015). ${ }^{12}$ Given the lack of public funding of elderly care, another concern that would invalidate this instrument would be if remittances or donations of migrants were used to contribute to improving the local infrastructure for example by financing private health services. Also, this is less of a concern in China. Social organizations

\footnotetext{
${ }^{11}$ The community survey is released only for the 2011 wave and refers to community information of the previous year, 2010.

${ }^{12}$ Examining community-level descriptive statistics based on local economic conditions, we find again no differences in the provision of elderly care facilities between communities with better economic performance and the remaining ones. Results are available from the authors upon request.
} 
and individuals are encouraged to donate money but the fraction of such donations is still very small (Liu 2013). Charities and non-profit organizations are extremely rare (Zhang and $\mathrm{Hu}$ 2014). Much in contrast to other developing countries, a high proportion of the income of migrants in China remains in urban areas. Remittances have not contributed to a substantial development of rural areas and have had only limited impact on the welfare of the families left-behind (Biao 2007).

\section{Results}

The main results of our fixed effects and instrumental variable estimations are reported in Table 2. Each cell refers to coefficient estimates of separate linear probability models in which we additionally control for a variety of factors that could influence an elderly's emotional health as described before. The first column reports OLS estimates which show correlations between the household's migration status and our emotional health indicators of elderly parents. The OLS estimates show that migration is associated with lower levels of happiness as well as significantly higher levels of loneliness and depressive symptoms.

Table 8 in the Appendix displays the determinants of the emotional health indicators without accounting for endogeneity. In line with Clark and Oswald (2002) and Easterlin (2004), we find that widowhood, difficulties in performing ADLs and IADLs as well as lower self-rated health ${ }^{13}$ are the most important determinants associated with considerably reduced emotional health of elderly parents. Our indicators are negatively related with age and gender and suggest that older men tend to have significantly better outcomes than women which is consistent with Lei et al. (2014). Child characteristics play a minor role. Elderly parents with better educated and married adult children tend to report on average better emotional health outcomes, consistent with the "healthy migrant" hypothesis.

The migration indicator is likely to be endogenous if unobserved characteristics affect both an adult child's migration decision and parental emotional health. For example, healthier and emotionally more stable adult children may be more likely to both migrate and to have emotionally healthier parents. Such unobserved timeinvariant factors that affect both the migration decision and parental emotional health are likely to underestimate the impact of migration on parental emotional health and they prevent us from interpreting the OLS results in a causal way. Fixed effects estimates eliminate the influence of such unobserved individual time-invariant characteristics and allow us to identify the effect of migration through the changes in the migration status of adult children over the survey years. As coefficient estimates are identified through changes in the time-varying control variables, this specification further allows us to account for major life events in the elderly's life that affect emotional health over and above an adult child's migration.

Coefficient estimates of the fixed effects specification are reported in the second column of Table 2. They reveal that parents in migrant households report to be 6.6

\footnotetext{
${ }^{13}$ Health is defined in categories of 1 indicating excellent self-rated health to 6 for poor self-rated health.
} 
Table 2 Effect of migration status of adult children's migration status on parental emotional health outcomes. (Each entry represents coefficient on the indicator for having at least one migrating adult child at the time of the survey)

\begin{tabular}{|c|c|c|c|c|}
\hline & \multirow[t]{2}{*}{ OLS } & \multirow[t]{2}{*}{ FE } & \multicolumn{2}{|l|}{ IV } \\
\hline & & & IV1 & IV2 \\
\hline \multicolumn{5}{|l|}{ Panel A: short-term indicators } \\
\hline Happy & $\begin{array}{l}-0.008 \\
(0.67)\end{array}$ & $\begin{array}{l}-0.066^{* * * *} \\
(2.61)\end{array}$ & $\begin{array}{l}-0.097 \\
(1.04)\end{array}$ & $\begin{array}{l}-0.106 \\
(1.14)\end{array}$ \\
\hline Lonely & $\begin{array}{l}0.032^{* * * *} \\
(3.15)\end{array}$ & $\begin{array}{l}0.033 * * \\
(1.99)\end{array}$ & $\begin{array}{c}0.021 \\
(0.28)\end{array}$ & $\begin{array}{c}0.016 \\
(0.22)\end{array}$ \\
\hline \multicolumn{5}{|l|}{ Panel B: longer-term indicators } \\
\hline Depressed & $\begin{array}{r}0.017 \\
(1.48)\end{array}$ & $\begin{array}{l}-0.016 \\
(0.69)\end{array}$ & $\begin{array}{r}0.015 \\
(0.18)\end{array}$ & $\begin{array}{c}0.008 \\
(0.10)\end{array}$ \\
\hline CES-D & $\begin{array}{l}0.448^{* * * *} \\
(3.15)\end{array}$ & $\begin{array}{l}0.761 * * * \\
(3.17)\end{array}$ & $\begin{array}{c}0.601 \\
(0.57)\end{array}$ & $\begin{array}{r}0.403 \\
(0.39)\end{array}$ \\
\hline \multicolumn{5}{|l|}{ First-stage results } \\
\hline Migrant population share & & & $\begin{array}{l}0.449 * * * \\
(10.71)\end{array}$ & $\begin{array}{l}0.453 * * * \\
(10.75)\end{array}$ \\
\hline Total revenues per capita & & & - & $\begin{array}{l}-0.000 \\
(0.95)\end{array}$ \\
\hline$F$-stat for excluded instruments & & & 114.66 & 57.87 \\
\hline Parental controls & Yes & Yes & Yes & Yes \\
\hline Household controls & Yes & Yes & Yes & Yes \\
\hline Adult child controls & Yes & Yes & Yes & Yes \\
\hline$N$ & 6198 & 6198 & 6198 & 6181 \\
\hline
\end{tabular}

$* p<0.1, * * p<0.05, * * * p<0.01$; robust standard errors, absolute $t$-statistics in parenthesis

The column labelled IV1 uses a community's migration share as instrument; the column labelled IV2 additionally uses total per capita revenues as instruments. Additional parental controls: dummy for being male, illiterate, having more than a high school degree, being widowed, having difficulties with ADLs and IADLs, agricultural Hukou, the number of children, two dummy variables indicating age as well as a variable on self-reported health status; additional children controls: age, dummies for being male, married, the oldest son and two education dummies. In addition we include province and time fixed effects

percentage points less happy and to feel 3.3 percentage points lonelier. Panel B shows that depressive symptoms of elderly parents are significantly worsened resulting from migration of at least one adult child. Although the estimates do not show that elderly parents feel systematically more depressed in the past week, our measure of clinical depressive symptoms is significantly increased. On average, the CES-D score is raised by 0.761 points when a household experiences changes in its migration status which compared to mean CES-D scores of 8.9 reveals severely augmented depressive symptoms. This pushes average scores among this group of elderly parents close to the cut-off of 10 suggesting clinically depressive symptoms. 
The difference between the FE estimates and those obtained from OLS is pronounced in most cases. This tells us that unobserved time-invariant sources of individual heterogeneity have an important impact on parental emotional health. A closer comparison of the magnitudes of the respective differences in coefficient estimates is in line with our expectation that migrants and their parents are positive selected in terms of emotional wellbeing, which leads to significantly downward biased OLS estimates of happiness and depressive symptoms.

Determinants of fixed effect regressions, as reported in Table 9 in the Appendix, confirm that a deterioration of physical health is highly related with worsening of emotional health. The occurrence of ADL limitations drastically increases CES-D scores and aggravates the feelings of loneliness and depression. It does however only marginally influence happiness probabilities. Similarly, elderly parents who report to have more difficulties with IADLs are found to have significantly increased depressive symptoms and are 6.6 percentage points less happy. Clearly, a deterioration of physical health adversely affects emotional health of the elderly parent, in line with Clark and Oswald (2002) and Easterlin (2004).

Other life events which occurred during the two survey waves have further contributed to worsened emotional health outcomes. For example a change in the number of children is positively associated with emotional health outcomes. This means that the loss of a child significantly impairs happiness and aggravates depressive symptoms. The loss of a spouse, measured as changes in widowhood, only marginally reduces the probability of being happy but leads to strongly CES-D scores. This supports findings of Easterlin (2004) who notes that self-rated emotional health adjusts rather slowly to widowhood.

A further concern is reverse causality and simultaneity between migration and parental emotional health both of which are not eliminated by fixed effects regressions. To this end, columns 3 and 4 of Table 2 report IV estimates using different sets of instruments. The column labelled IV1 reports results using only community variations in the migration share as instrumental variable, whereas in the column labelled IV2, we add the community's local economic conditions. Results of IV regressions crucially depend on the choice of instruments. To evaluate the strength of our instruments, Table 2 illustrates first-stage results of the instruments on the household's migration status. The table shows that variations in a community's share of migrants are highly positively correlated with the probability of a household of having at least one migrant child. This is in line with our expectation that a larger migrant network facilitates migration by reducing its costs and hence increasing the probability of new migration (Rozelle et al. 1999; Mckenzie and Rapoport 2007; Fan 2008). The second instrumental variable using community variations of per capita revenues in 2010 is negatively related with the household's migration status, as expected, but the coefficient estimate is not statistically significant. The first-stage $F$-statistics on excluded instruments, as reported by Table 2, are larger than 10 in both cases, suggesting that our instruments are strong (Stock and Yogo 2002; Angrist and Pischke 2009). The results of the Hansen $J$ statistic, which are not reported here, ${ }^{14}$ further show that the

\footnotetext{
${ }^{14}$ Results are available from the authors upon request.
} 
instruments are appropriately uncorrelated with the error terms and that the set of instruments is over-identified in all cases.

In general, the IV coefficient estimates are in line with previous findings and strengthen the strongly negative impact of migration of an adult child on parental emotional health. Note that due to different samples and sources of variations the IV coefficients are not easily comparable to those obtained from OLS and fixed effects regressions. The IV strategy is not able to detect augmented probabilities of feeling lonely or depressed in the past week. In contrast, we find that elderly parents are about 11 percentage points less likely to be happy and CES-D scores are between 0.4 and 0.6 points higher. The IV coefficient estimates are substantially larger in absolute values compared to the OLS estimates. This provides further support that migrating children as well as their elderly parents are likely to be positively selected in terms of physical and emotional health which leads to OLS estimates being biased towards zero. Moreover, the IV estimates are imprecisely measured. This may stem from differences in the population considered by the variations of the instrumental variables. In our IV strategy, we exploit different sources of variation in the migration decision that mainly originate from variations in the instrumental variables, whereas OLS estimates refer to the entire elderly population (Oreopoulos 2006). In this respect, the larger IV estimates may indicate that the impact of migration on emotional health is particularly pronounced for elderly who live in communities with large migration network or in communities that have worse local economic conditions. Despite these differences in the magnitudes of IV and OLS coefficient estimates, our results are indicative of a causal relationship between the household's migration status and significantly exacerbated parental emotional health.

\section{Robustness checks}

So far, we measured the effect of migration by a dummy variable which takes the value of 1 if at least one of the adult children has migrated outside of the home county or abroad. In the remainder of this section, we will look at the effect of migration based on different migration definitions.

\subsection{Redefining the migration variable}

The impact of migration on parental emotional health is expected to be more pronounced if more children and in particularly if more sons migrate. To this end, we redefine migrants by the number of migrating children, the number of migrant sons as well as the fraction of migrant children (sons) relative to all children in a household as alternative measures for migration. Table 3 shows the results.

Independent of the measure used, we find consistent and strong adverse effects of migration on parental emotional health. More specifically, a higher number of migrated adult children but more so, a higher number of migrated sons reduces the probability of elderly parents being happy and lead to deteriorated feelings of loneliness and depressive symptoms. According to Confucian tradition, sons and their families are the main providers of elderly care which means that a shrinking 
Table 3 The effects of children's migration status on parental emotional health outcomes using different definitions of the migration variable (each entry in the table represents coefficient estimates for different definitions of the migration variable)

\begin{tabular}{|c|c|c|c|c|c|c|}
\hline & OLS & $\mathrm{FE}$ & IV & OLS & FE & IV \\
\hline & Happy & & & Lonely & & \\
\hline $\begin{array}{l}\text { No. of migrant } \\
\text { children }\end{array}$ & $\begin{array}{l}0.005 \\
(0.89)\end{array}$ & $\begin{array}{l}-0.016 \\
(1.30)\end{array}$ & $\begin{array}{l}-0.039 \\
(1.04)\end{array}$ & $\begin{array}{l}0.010^{* *} \\
(2.24)\end{array}$ & $\begin{array}{l}0.006 \\
(0.72)\end{array}$ & $\begin{array}{l}0.008 \\
(0.28)\end{array}$ \\
\hline $\begin{array}{l}\text { No. of migrant } \\
\text { sons }\end{array}$ & $\begin{array}{l}-0.003 \\
(0.30)\end{array}$ & $\begin{array}{l}-0.027 \\
(1.64)\end{array}$ & $\begin{array}{l}-0.049 \\
(1.04)\end{array}$ & $\begin{array}{l}0.011^{*} \\
(1.70)\end{array}$ & $\begin{array}{c}0.002 \\
(0.16)\end{array}$ & $\begin{array}{r}0.011 \\
(0.28)\end{array}$ \\
\hline $\begin{array}{l}\% \text { of migrant } \\
\text { children }\end{array}$ & $\begin{array}{r}0.010 \\
(0.50)\end{array}$ & $\begin{array}{l}-0.096^{* *} \\
(2.31)\end{array}$ & $\begin{array}{l}-0.127 \\
(1.03)\end{array}$ & $\begin{array}{l}0.039^{* *} \\
(2.53)\end{array}$ & $\begin{array}{r}0.030 \\
(1.06)\end{array}$ & $\begin{array}{r}0.027 \\
(0.28)\end{array}$ \\
\hline \multirow[t]{2}{*}{$\begin{array}{l}\% \text { of migrant } \\
\text { sons }\end{array}$} & $\begin{array}{l}-0.005 \\
(0.16)\end{array}$ & $\begin{array}{l}-0.101^{*} \\
(1.80)\end{array}$ & $\begin{array}{l}-0.166 \\
(1.03)\end{array}$ & $\begin{array}{c}0.034 \\
(1.59)\end{array}$ & $\begin{array}{l}-0.006 \\
(0.17)\end{array}$ & $\begin{array}{l}0.035^{\text {**** }} \\
(0.28)\end{array}$ \\
\hline & Depressed & & & CES-D & & \\
\hline $\begin{array}{l}\text { No. of migrant } \\
\text { children }\end{array}$ & $\begin{array}{c}0.002 \\
(0.33)\end{array}$ & $\begin{array}{r}0.001 \\
(0.08)\end{array}$ & $\begin{array}{r}0.006 \\
(0.18)\end{array}$ & $\begin{array}{c}0.033 \\
(0.50)\end{array}$ & $\begin{array}{l}0.238^{* *} \\
(2.26)\end{array}$ & $\begin{array}{c}0.244 \\
(0.57)\end{array}$ \\
\hline $\begin{array}{l}\text { No. of migrant } \\
\text { sons }\end{array}$ & $\begin{array}{l}-0.005 \\
(0.64)\end{array}$ & $\begin{array}{c}0.002 \\
(0.13)\end{array}$ & $\begin{array}{r}0.008 \\
(0.18)\end{array}$ & $\begin{array}{r}0.065 \\
(0.71)\end{array}$ & $\begin{array}{r}0.047 \\
(0.32)\end{array}$ & $\begin{array}{r}0.305 \\
(0.57)\end{array}$ \\
\hline $\begin{array}{l}\% \text { of migrant } \\
\text { children }\end{array}$ & $\begin{array}{r}0.000 \\
(0.01)\end{array}$ & $\begin{array}{c}0.020 \\
(0.55)\end{array}$ & $\begin{array}{r}0.020 \\
(0.18)\end{array}$ & $\begin{array}{c}0.258 \\
(1.13)\end{array}$ & $\begin{array}{l}1.085^{* * *} \\
(2.95)\end{array}$ & $\begin{array}{r}0.791 \\
(0.57)\end{array}$ \\
\hline $\begin{array}{l}\% \text { of migrant } \\
\text { sons }\end{array}$ & $\begin{array}{l}-0.018 \\
(0.71)\end{array}$ & $\begin{array}{l}-0.008 \\
(0.17)\end{array}$ & $\begin{array}{r}0.026 \\
(0.18)\end{array}$ & $\begin{array}{r}0.179 \\
(0.59)\end{array}$ & $\begin{array}{r}0.031 \\
(0.06)\end{array}$ & $\begin{array}{r}1.031 \\
(0.57)\end{array}$ \\
\hline
\end{tabular}

$* p<0.10, * * p<0.05$, *** $p<0.01$; robust standard errors, absolute $t$-statistics in parenthesis

Additional parental controls: dummy for being male, illiterate, having more than a high school degree, being widowed, having difficulties with ADLs and IADLs, agricultural Hukou, the number of children two dummy variables indicating age as well as a variable on self-reported health status; additional children controls: age, dummies for being male, married, the oldest son and two education dummies. In addition we include province and time fixed effects

support network drastically impairs emotional health. Fixed effects regressions are only able to identify worsened feelings of happiness and depressive symptoms from the migration of an additional child/son.

\subsection{Exploring the dynamics of the adult child's migration status}

Our fixed effects approach allowed us to examine the dynamics of changes in a household's migration status during the survey waves on emotional health outcomes of elderly parents. The strength of these effects is likely to depend on the direction of an adult child's migration: we expect the adverse effect on emotional health of a newly migrating adult child to be stronger than the mitigating impact of return migration. 


\subsubsection{Modelling approach and description of variables}

To be precise, we distinguish between the differential effects of newly migrating and return migrating adult children. For this exercise, we proceed in two different ways. In a first approach, we define dummy variables for returning and newly migrating children and examine parental emotional health outcomes prior to the migration decision (2011) and afterwards (2013), separately. To reduce the risk of introducing further sources of endogeneity, we control only for pre-determined characteristics of 2011 and estimate the following model:

$$
\text { Wellbeing }_{i t}=\beta_{0}+\gamma_{1} R M_{i}+\gamma_{2} N M_{i}+\mathbf{P}_{i, 2011} \beta_{1}+\mathbf{C}_{i, 2011} \beta_{2}+\epsilon_{i, 2011},
$$

where Wellbeing ${ }_{i t}$ refers to the same emotional health indicators as used before for elderly parent $i$ in year $t ; R M_{i}$ is a dummy variable which takes the value 1 if the household experienced return migration in 2013 and $N M_{i}$ for the case of new migration. More specifically, a household is defined as a return (newly) migrating household if it had at least one (no) migrant child in 2011 and none (at least one) in 2013. There are 59 elderly parents living in 12 households who observed both of these changes. ${ }^{15}$ We exclude these households from this analysis. The vectors $\mathbf{P}_{i, 2011}$ and $\mathbf{C}_{i, 2011}$ control for parental and child characteristics for 2011, respectively and $\epsilon_{i, 2011}$ is the error term. We estimate this model using OLS. This approach allows us to isolate the effect of changes in the household's migration status on parental emotional health holding all other characteristics constant.

In a second estimation strategy, we re-estimate (1) using a fixed effect specification restricted to the sample of households which experience return or new migration between 2011 and 2013 compared to households whose migration status has not changed. Using this approach, we are able to examine the added effect of return and new migration by simultaneously accounting for major life events that have occurred in the elderly parent's life between the two periods and which may have affected emotional health over and above the adult child's migration decision.

Descriptive statistics for returning or newly migrating adult children are presented in Table 4. Returning children tend to be more than a year younger on average compared to adult children who have not changed their migration status. They are less likely to be married but are more likely to be male and the oldest son of the family. This is consistent with Confucian beliefs that sons and their families are the main care takers of their parents in old age. Elderly parents of returning migrants are found to be slightly younger on average and to have fewer children which might result in increased pressure among the adult children regarding the care of elderly parents. Newly migrating children, in contrast, tend to be more likely to be married. Their parents tend to be more likely to be illiterate and to have significantly fewer difficulties with ADLs and IADLs which is consistent with the "healthy migrant" hypothesis (Farré 2015).

\footnotetext{
${ }^{15}$ In all of these households, one child returned and another one newly migrated.
} 
Table 4 Descriptive statistics for returning and newly migrating children for 2013

\begin{tabular}{|c|c|c|c|c|c|c|}
\hline & \multicolumn{3}{|c|}{ Return migrants } & \multicolumn{3}{|c|}{ New migrants } \\
\hline & Mean & s.d. & $\Delta$ & Mean & s.d. & $\Delta$ \\
\hline \multicolumn{7}{|l|}{ Parent characteristics } \\
\hline Age & 68.680 & $(7.15)$ & -0.515 & 68.784 & $(7.31)$ & -0.411 \\
\hline Widowed & 0.286 & $(0.45)$ & -0.011 & 0.305 & $(0.46)$ & 0.008 \\
\hline Male & 0.558 & $(0.50)$ & -0.035 & 0.563 & $(0.50)$ & -0.029 \\
\hline Illiterate & 0.301 & $(0.46)$ & -0.001 & 0.366 & $(0.48)$ & $0.064 * *$ \\
\hline More than high school & 0.048 & $(0.22)$ & -0.008 & 0.033 & $(0.18)$ & 0.023 \\
\hline $\mathrm{ADL}$ & 0.086 & $(0.28)$ & -0.002 & 0.052 & $(0.22)$ & $-0.036^{*}$ \\
\hline IADL & 0.156 & $(0.36)$ & -0.039 & 0.122 & $(0.33)$ & $-0.073 * * *$ \\
\hline No. of adult children & 3.416 & $(1.52)$ & $-0.327 * * *$ & 3.718 & $(1.63)$ & -0.025 \\
\hline \multicolumn{7}{|l|}{ Child characteristics } \\
\hline Age & 40.613 & $(6.43)$ & $-1.084 * *$ & 41.319 & $(7.41)$ & -0.378 \\
\hline Illiterate & 0.052 & $(0.22)$ & -0.022 & 0.052 & $(0.22)$ & -0.023 \\
\hline More than high school & 0.108 & $(0.31)$ & 0.011 & 0.127 & $(0.33)$ & 0.030 \\
\hline Male & 0.628 & $(0.48)$ & $0.145^{* * *}$ & -0.516 & $(0.50)$ & 0.033 \\
\hline Married & 0.896 & $(0.31)$ & $-0.055^{* * *}$ & 0.915 & $(0.28)$ & $-0.036^{* *}$ \\
\hline Oldest son & 0.368 & $(0.48)$ & $0.094^{* * * *}$ & 0.258 & $(0.44)$ & -0.016 \\
\hline$N$ & 269 & & & 213 & & \\
\hline
\end{tabular}

$* p<0.1, * * p<0.05, * * * p<0.01$; standard deviations in parenthesis

Columns labelled $\Delta$ present differences in means compared to mean characteristics of children who have not changed their migration status. Negative values indicate larger mean values for the reference groups. Return (new) migrants refer to adult children who migrated (stayed in their registered place) in 2011 and return (newly) migrated in 2013

\subsubsection{Results}

Conditioning on characteristics of 2011, findings by survey wave are reported in Table 5. While parents of returning migrants tend to report drastically worsened emotional health outcomes prior to taking the decision to return, it is mainly depressive symptoms that have worsened after adult children have decided to newly migrate. This is an important finding as it suggests that parental emotional heath in our sample is likely to affect the decision to return migrate but is not related to the decision to newly migrate.

Estimates in Table 5 indicate that elderly parents in returning households are 7.8 percentage points less happy and report to feel 4.2 percentage points lonelier prior to the change in the household's migration status. Upon return, these parents feel significantly less depressed but their CES-D are hardly unchanged. This suggests that parent's emotional wellbeing responds strongly to the return of a child if everything else is unchanged. 
Table 5 The effect of return and new migration on emotional health in 2011 and 2013 based on predetermined characteristics for 2011

\begin{tabular}{|c|c|c|c|c|}
\hline & \multicolumn{2}{|c|}{ New migrant } & \multicolumn{2}{|c|}{ Returning migrant } \\
\hline & 2011 & 2013 & 2011 & 2013 \\
\hline \multicolumn{5}{|l|}{ Panel A: short-run indicators } \\
\hline Happy & $\begin{array}{l}0.019 \\
(0.83)\end{array}$ & $\begin{array}{c}0.033 \\
(1.25)\end{array}$ & $\begin{array}{l}-0.078^{* * *} \\
(3.24)\end{array}$ & $\begin{array}{c}0.002 \\
(0.09)\end{array}$ \\
\hline Lonely & $\begin{array}{r}0.007 \\
(0.33)\end{array}$ & $\begin{array}{l}-0.007 \\
(0.38)\end{array}$ & $\begin{array}{l}0.042^{* *} \\
(2.03)\end{array}$ & $\begin{array}{l}-0.011 \\
(0.63)\end{array}$ \\
\hline \multicolumn{5}{|l|}{ Panel B: longer-run indicators } \\
\hline Depressed & $\begin{array}{l}0.119 * * * \\
(5.03)\end{array}$ & $\begin{array}{c}0.023 \\
(1.02)\end{array}$ & $\begin{array}{c}0.041^{*} \\
(1.86)\end{array}$ & $\begin{array}{l}-0.010 \\
(0.45)\end{array}$ \\
\hline CES-D & $\begin{array}{r}0.357 \\
(1.26)\end{array}$ & $\begin{array}{l}0.887 * * * \\
(3.25)\end{array}$ & $\begin{array}{c}0.361 \\
(1.21)\end{array}$ & $\begin{array}{c}0.206 \\
(0.75)\end{array}$ \\
\hline Parental controls-2011 & Yes & Yes & Yes & Yes \\
\hline Household controls—2011 & Yes & Yes & Yes & Yes \\
\hline Adult child controls_-2011 & Yes & Yes & Yes & Yes \\
\hline
\end{tabular}

$* p<0.10, * * p<0.05, * * * p<0.01$; robust standard errors, absolute $t$-statistics in parenthesis

Additional parental controls based on 2011 characteristics: dummy for being male, illiterate, having more than a high school degree, being widowed, having difficulties with ADLs and IADLs, agricultural Hukou, the number of children two dummy variables indicating age as well as a variable on self-reported health status; additional children controls: age, dummies for being male, married, the oldest son and two education dummies. In addition we include province and time fixed effects

In the case of newly migrating adult children, we find no differences in short-term emotional health indicators of the elderly parent such as happiness and loneliness before the migration decision is made. The only exception is that parents are more likely to feel depressed in the week prior to the interview. Once the household experiences outmigration of an adult child, elderly parents feel 2.3 percentage points more depressed and CES-D scores increased by 0.887 points which indicates severely aggravated overall levels of depressive symptoms.

These findings are conditioned on pre-determined characteristics of the first survey wave. This approach allows us to isolate the impact of changes in the household's migration status on parental emotional health had everything else remained the same. By restricting the sample to only returning or newly migrating children, respectively and by estimating the model using fixed effects specifications allows us to assess additionally the importance of controlling for major life events that have occurred in an elderly parent's life between the two survey years. Findings are reported in Table 6 .

The results in Table 6 indicate that parents of return migrating adult children report to be 8.3 percentage points unhappier but they also feel slightly less lonely and have slightly reduced CES-D scores. In households with newly migrating children, happiness levels are reduced by 9.4 percentage points and elderly parents also report to 
Table 6 Effect of return and new migration on changes in emotional health based on restricted fixedeffects specifications

\begin{tabular}{lllll}
\hline & Happy & Lonely & Depressed & CES-D \\
\hline Return migrant household & $-0.083^{* *}$ & -0.023 & -0.012 & -0.355 \\
& $(1.98)$ & $(0.90)$ & $(0.22)$ & $(0.93)$ \\
New migrant household & $-0.094^{* *}$ & 0.044 & 0.013 & $1.989^{* * *}$ \\
& $(2.37)$ & $(1.44)$ & $(0.34)$ & $(5.66)$ \\
Parental controls & Yes & Yes & Yes & Yes \\
Household controls & Yes & Yes & Yes & Yes \\
Adult child controls & Yes & Yes & Yes & Yes \\
\hline
\end{tabular}

$* p<0.10, * * p<0.05, * * * p<0.01$; robust standard errors, absolute $t$-statistics in parenthesis

Additional parental controls: age, being widowed, the number of children, health status, dummies for ADL and IADL limitations, agricultural Hukou; additional children controls: age, marital status

be 4.4 percentage points lonelier. More worryingly, elderly parents CES-D scores are increased by 2 points.

A comparison of the results presented in Tables 5 and 6 allows us to assess additionally the importance of major life events on emotional health over and above changes in the migration decision. Interestingly, a parent's level of happiness in return migrant households is found to be significantly reduced if major life events are accounted for (Table 6). This may suggest that adult children are likely to take the decision to return migrate during hard times when elderly parents need additional support from their adult children. The significantly worsened feelings of happiness and depression are to a large extent explained by deteriorations in limitations with ADLs and IADLs over time but also by other life events such as the loss of a child or a spouse. It is therefore likely that the decision of an adult child to return migrate is driven by the elderly parent's physical and emotional health. As noted before, by not accounting for such major changes, OLS estimates are significantly downward biased.

Major life events have also significantly worsened the impact of migration on CES-D scores. Lei et al. (2014) examine the determinants of increased depressive symptoms in China using only the first wave of the CHARLS data. They find very high levels but are not able to examine reasons for the increased occurrence of depressive symptoms in China since the 1980s as well as the large dispersion across groups. Combined with their finding, our results suggest that migration is an important channel leading to significantly aggravated mental health which could be mitigated by return migration.

\section{Conclusion}

As a result of two main demographic phenomena in China, ageing and large-scale internal migration without a national pension system and with lacking formal institutional support mechanisms such as nursing homes, the situation for elderly parents in 
rural China is severely exacerbating. In this context, we are concerned with the effect of out-migration of adult children on the emotional health of elderly parents.

Our main findings suggest that the emotional health of an elderly parent significantly deteriorates if an adult child migrates. This holds independently of the estimation strategy, FE and IV, which rely on different sources of variation to identify these effects. We find that migration reduces the level of happiness by 6.6 percentage points and leads to a 3.4 percentage points higher probability of loneliness. Our results are robust to different migrant definitions. Given that all strategies used in this paper lead to the same conclusion, we are confident with the robustness of our results. Moreover, our results are indicative of a causal relationship between migration and significant deteriorations of parental emotional health.

It is important to note that migrants in China tend to be young, unmarried and to have no children (Knight et al. 1999; Zhao 1999; Démurger et al. 2009). This implies that the many of the migrant adult children in our sample with parents aged 60 or older are likely to have taken their migration decision in the past when they were younger and less dependent on other household members. This means that our sample of elderly parents has been affected by the associated adverse effects of the migration decision of their children for a potentially extended period of time. In an alternative definition of emotional health based on a more clinical indicator of depressive symptoms, it is confirmed that the emotional health of elderly parents with migrant children is severely exacerbated. This is worrying as it pushes average scores for this group of parents close to the cut-off point indicating clinical levels of depressive symptoms.

We further examine adjustments in emotional health outcomes by separating the impact of return and new migration. Our results reveal that by isolating the impact of changes in the household's migration status, an elderly parent's emotional health is likely to affect an adult child's decision to return migrate but is not related to the decision to newly migrate. While an elderly parent's depressive symptoms dramatically deteriorate when an adult child migrates, we find that emotional health ameliorates quickly upon the return of a migrant child. Although parent's emotional health does not differ systematically before a new migration episode, we observe that parents of newly migrating children are significantly less likely to be of poor physical health which supports the "healthy migrant effect" (Farré 2015). When additionally accounting for major life events which have occurred in an elderly parent's life, we find that the adult child's decision to return migrate is largely driven by the elderly's physical health status as well as by the loss of a child or a spouse which drastically impair emotional wellbeing and require additional emotional support from an adult child.

The United Nations (2013) anticipated for China that by 2050, the elderly support ratio, i.e. the number of elderly aged 65 or above divided by the number of population aged between 25 and 64, will sharply decrease to 1:2 compared to the ratio of $1: 13$ in 2000. This drastic reduction will place an even greater strain on the traditional elderly supporting mechanisms prevalent in China. This is an important issue not only because the rural elderly are a highly vulnerable and disadvantaged group within society but also because the shrinking number of adult children will face an even higher supporting pressure. The Chinese government has put various reforms in place to improve the social support of the elderly. For example, the revised version of the "Law on Protection of Rights and Interests of Seniors" explicitly states 
that children are obliged to provide financial, physical and psychological support for their parents, even though the enforcement can hardly be guaranteed. These pilot regulations, however, have often been criticized of having a too narrow coverage and of being inefficient. Therefore, mature, established and well-functioning security and pension systems are an extremely urgent matter for China given the dramatic demographic population outlook.

Acknowledgements We thank the editor Klaus Zimmermann and three anonymous referees for their very helpful comments and suggestions.

\section{Compliance with Ethical Standards}

Conflict of interest The authors declare that they have no competing interests.

Open Access This article is distributed under the terms of the Creative Commons Attribution 4.0 International License (http://creativecommons.org/licenses/by/4.0/), which permits unrestricted use, distribution, and reproduction in any medium, provided you give appropriate credit to the original author(s) and the source, provide a link to the Creative Commons license, and indicate if changes were made.

\section{Appendix}

Table 7 Aggregate descriptive statistics for community characteristics by strength of the migrant network

\begin{tabular}{|c|c|c|c|c|c|}
\hline & \multicolumn{2}{|c|}{ Weak networks } & \multicolumn{2}{|c|}{ Strong networks } & \multirow{2}{*}{$\begin{array}{l}\Delta \\
p \text { value }\end{array}$} \\
\hline & Mean & std & Mean & std & \\
\hline \multicolumn{6}{|l|}{ Parent generation } \\
\hline Age & 63.710 & 3.599 & 63.507 & 3.666 & 0.674 \\
\hline Education & 3.058 & 0.814 & 3.001 & 0.773 & 0.593 \\
\hline No. of children & 3.052 & 0.6545 & 3.149 & 0.583 & 0.236 \\
\hline \multicolumn{6}{|l|}{ Adult child generation } \\
\hline Age & 36.577 & 3.148 & 36.277 & 3.341 & 0.486 \\
\hline Education & 4.861 & 0.797 & 4.742 & 0.759 & 0.249 \\
\hline \multicolumn{6}{|l|}{ Community } \\
\hline Land expropriation & 0.449 & 0.499 & 0.408 & 0.494 & 0.534 \\
\hline Paved roads as main type of roads & 0.732 & 0.445 & 0.602 & 0.492 & $0.036 * *$ \\
\hline$\%$ of households use electricity & 99.890 & 0.911 & 99.854 & 1.023 & 0.782 \\
\hline Elderly association & 0.299 & 0.460 & 0.252 & 0.437 & 0.433 \\
\hline Nursing home & 0.087 & 0.282 & 0.087 & 0.284 & 0.918 \\
\hline Elderly care centre & 0.031 & 0.175 & 0.029 & 0.169 & 0.918 \\
\hline Population & 3032 & 2990 & 2532 & 2450 & 0.173 \\
\hline Per capita income & 5006 & 4488 & 4695 & 6172 & 0.659 \\
\hline Maximum temperature & 37.091 & 3.296 & 37.204 & 2.982 & 0.787 \\
\hline Minimum temperature & -7.787 & 10.357 & -7.971 & 11.976 & 0.897 \\
\hline
\end{tabular}


Table 7 (continued)

\begin{tabular}{|c|c|c|c|c|c|}
\hline & \multicolumn{2}{|c|}{ Weak networks } & \multicolumn{2}{|c|}{ Strong networks } & \multirow{2}{*}{$\begin{array}{l}\Delta \\
p \text { value }\end{array}$} \\
\hline & Mean & std & Mean & std & \\
\hline$\%$ with hukou in this village & 0.864 & 0.235 & 0.910 & 0.191 & 0.110 \\
\hline Minorities & 0.472 & 0.501 & 0.485 & 0.502 & 0.845 \\
\hline$\%$ of adults being illiterate & 10.359 & 8.837 & 11.257 & 10.917 & 0.491 \\
\hline$\%$ of adults with primary school & 28.077 & 17.500 & 28.540 & 18.258 & 0.845 \\
\hline$\%$ of adults with junior high school & 38.384 & 16.182 & 38.430 & 16.686 & 0.983 \\
\hline$\%$ of adults with senior high school & 16.926 & 9.783 & 15.298 & 8.943 & 0.194 \\
\hline$\%$ of adults with college degree & 4.274 & 4.688 & 3.699 & 4.068 & 0.327 \\
\hline$\%$ of adults with more than college & 0.409 & 0.494 & 0.398 & 0.492 & 0.862 \\
\hline$N$ & 127 & & & 103 & \\
\hline
\end{tabular}

$* p<0.1, * * p<0.05, * * * p<0.01$. A community with a strong migrant network is defined as having more than the mean share of migrants across all communities

Table 8 Determinants of linear probability models between emotional health outcomes and children's migration status. (Dependent variables: dummies for being happy, being depressed and being lonely)

\begin{tabular}{|c|c|c|c|c|}
\hline & Happy & Lonely & Depressed & CES-D \\
\hline Migrant child & $\begin{array}{l}-0.008 \\
(0.67)\end{array}$ & $\begin{array}{l}0.032^{* * * *} \\
(3.15)\end{array}$ & $\begin{array}{c}0.017 \\
(1.48)\end{array}$ & $\begin{array}{l}0.448^{* * * *} \\
(3.15)\end{array}$ \\
\hline Parent: aged $[70 ; 80]$ & $\begin{array}{c}0.026 \\
(1.64)\end{array}$ & $\begin{array}{l}-0.034 * * * \\
(2.64)\end{array}$ & $\begin{array}{l}-0.028^{*} \\
(1.89)\end{array}$ & $\begin{array}{l}-0.880^{* * * *} \\
(4.86)\end{array}$ \\
\hline Parent: aged above 80 & $\begin{array}{c}0.038 \\
(1.30)\end{array}$ & $\begin{array}{l}-0.059 * * \\
(2.39)\end{array}$ & $\begin{array}{l}-0.006 \\
(0.24)\end{array}$ & $\begin{array}{l}-0.207 \\
(0.60)\end{array}$ \\
\hline Parent: male & $\begin{array}{l}0.065^{* * * *} \\
(4.45)\end{array}$ & $\begin{array}{l}-0.059 * * * \\
(4.88)\end{array}$ & $\begin{array}{l}-0.169^{* * *} \\
(12.37)\end{array}$ & $\begin{array}{l}-2.246^{* * *} \\
(13.50)\end{array}$ \\
\hline Parent: widowed & $\begin{array}{l}-0.002 \\
(0.13)\end{array}$ & $\begin{array}{l}0.203^{* * *} \\
(14.50)\end{array}$ & $\begin{array}{l}-0.043^{* * *} \\
(3.04)\end{array}$ & $\begin{array}{l}0.428 * * \\
(2.38)\end{array}$ \\
\hline Parent: ADL limitation & $\begin{array}{c}0.000 \\
(0.00)\end{array}$ & $\begin{array}{l}0.066^{* * * *} \\
(3.08)\end{array}$ & $\begin{array}{l}0.148^{* * * *} \\
(6.21)\end{array}$ & $\begin{array}{l}2.127 * * * \\
(7.32)\end{array}$ \\
\hline Parent: IADL limitation & $\begin{array}{l}-0.078^{* * * *} \\
(4.30)\end{array}$ & $\begin{array}{c}0.012 \\
(0.81)\end{array}$ & $\begin{array}{l}0.039 * * \\
(2.21)\end{array}$ & $\begin{array}{l}1.749 * * * \\
(7.84)\end{array}$ \\
\hline Parent: health status & $\begin{array}{l}-0.102 * * * \\
(15.36)\end{array}$ & $\begin{array}{l}0.065^{* * *} \\
(11.78)\end{array}$ & $\begin{array}{l}0.105 * * * \\
(17.03)\end{array}$ & $\begin{array}{l}2.055^{* * * *} \\
(27.34)\end{array}$ \\
\hline Parent: number of children & $\begin{array}{l}-0.003 \\
(0.71)\end{array}$ & $\begin{array}{l}-0.010 * * * \\
(2.94)\end{array}$ & $\begin{array}{c}0.004 \\
(0.99)\end{array}$ & $\begin{array}{c}0.023 \\
(0.48)\end{array}$ \\
\hline Child: age & $\begin{array}{l}-0.000 \\
(0.28)\end{array}$ & $\begin{array}{l}-0.001 \\
(1.16)\end{array}$ & $\begin{array}{l}-0.002 * * \\
(2.17)\end{array}$ & $\begin{array}{l}-0.029 * * \\
(2.25)\end{array}$ \\
\hline Child: illiterate & $\begin{array}{l}-0.089 * * * \\
(3.66)\end{array}$ & $\begin{array}{l}-0.008 \\
(0.38)\end{array}$ & $\begin{array}{l}0.052 * * \\
(2.28)\end{array}$ & $\begin{array}{l}0.716^{* *} \\
(2.56)\end{array}$ \\
\hline
\end{tabular}


Table 8 (continued)

\begin{tabular}{lclll}
\hline & Happy & Lonely & Depressed & CES-D \\
\hline Child: above high school & $0.047^{* *}$ & $-0.032^{* * *}$ & $-0.064^{* * *}$ & $-0.885^{* * * *}$ \\
& $(2.26)$ & $(2.18)$ & $(3.61)$ & $(4.28)$ \\
Child: male & 0.011 & $-0.026^{* *}$ & $-0.024^{*}$ & -0.145 \\
& $(0.72)$ & $(2.08)$ & $(1.71)$ & $(0.83)$ \\
Child: married & $0.056^{* *}$ & 0.025 & -0.035 & $-0.707^{* *}$ \\
& $(2.09)$ & $(1.15)$ & $(1.43)$ & $(2.28)$ \\
$N$ & 6198 & 6198 & 6198 & 6198 \\
\hline
\end{tabular}

$* p<0.1, * * p<0.05, * * * p<0.01$; robust standard errors, absolute $t$-statistics in parenthesis

Additional children controls: being the oldest son, agricultural Hukou; province and time fixed effects

Table 9 Determinants from FE regressions between emotional health outcomes and children's migration status. (Dependent variables: dummies for being happy, being depressed and being lonely)

\begin{tabular}{|c|c|c|c|c|}
\hline & Happy & Lonely & Depressed & CES-D \\
\hline Migrant child & $\begin{array}{l}-0.066^{* * * *} \\
(2.61)\end{array}$ & $\begin{array}{l}0.033^{* *} \\
(1.99)\end{array}$ & $\begin{array}{l}-0.016 \\
(0.69)\end{array}$ & $\begin{array}{l}0.761 * * * \\
(3.17)\end{array}$ \\
\hline Parent: aged $[70 ; 80]$ & $\begin{array}{c}0.023 \\
(0.61)\end{array}$ & $\begin{array}{c}0.038 \\
(1.43)\end{array}$ & $\begin{array}{c}0.034 \\
(1.02)\end{array}$ & $\begin{array}{c}0.058 \\
(0.16)\end{array}$ \\
\hline Parent: aged above 80 & $\begin{array}{l}0.225^{* * *} \\
(2.96)\end{array}$ & $\begin{array}{l}-0.094 \\
(1.51)\end{array}$ & $\begin{array}{l}-0.051 \\
(0.78)\end{array}$ & $\begin{array}{l}-2.055^{* * *} \\
(2.67)\end{array}$ \\
\hline Parent: widowed & $\begin{array}{l}0.021 \\
(0.43)\end{array}$ & $\begin{array}{l}-0.032 \\
(0.78)\end{array}$ & $\begin{array}{l}-0.110^{* *} \\
(2.11)\end{array}$ & $\begin{array}{l}-1.410^{* * *} \\
(2.66)\end{array}$ \\
\hline Parent: ADL limitation & $\begin{array}{c}0.020 \\
(0.59)\end{array}$ & $\begin{array}{l}0.089 * * * \\
(2.99)\end{array}$ & $\begin{array}{l}0.115^{* * *} \\
(3.17)\end{array}$ & $\begin{array}{l}1.756^{* * * *} \\
(5.32)\end{array}$ \\
\hline Parent: IADL limitation & $\begin{array}{l}-0.062^{* * *} \\
(2.35)\end{array}$ & $\begin{array}{l}-0.028 \\
(1.34)\end{array}$ & $\begin{array}{l}0.064 * * \\
(2.49)\end{array}$ & $\begin{array}{l}1.475^{* * * *} \\
(5.31)\end{array}$ \\
\hline Parent: health Status & $\begin{array}{l}-0.039 * * * \\
(3.51)\end{array}$ & $\begin{array}{l}0.017^{*} \\
(1.88)\end{array}$ & $\begin{array}{c}0.000 \\
(0.05)\end{array}$ & $\begin{array}{l}0.604^{* * * *} \\
(5.45)\end{array}$ \\
\hline Parent: number of children & $\begin{array}{l}0.022 * \\
(1.81)\end{array}$ & $\begin{array}{l}-0.007 \\
(0.70)\end{array}$ & $\begin{array}{l}-0.045^{* * *} \\
(4.00)\end{array}$ & $\begin{array}{l}-0.183 \\
(1.59)\end{array}$ \\
\hline Child: age & $\begin{array}{l}-0.075^{* * * *} \\
(3.96)\end{array}$ & $\begin{array}{l}-0.046^{* * * *} \\
(3.34)\end{array}$ & $\begin{array}{l}-0.036^{* *} \\
(2.03)\end{array}$ & $\begin{array}{l}-0.151 \\
(0.94)\end{array}$ \\
\hline Child: married & $\begin{array}{l}-0.100^{*} \\
(1.80)\end{array}$ & $\begin{array}{l}-0.032 \\
(0.74)\end{array}$ & $\begin{array}{l}-0.095 \\
(1.64)\end{array}$ & $\begin{array}{l}-0.957 \\
(1.58)\end{array}$ \\
\hline$N$ & 6185 & 6185 & 6185 & 6185 \\
\hline
\end{tabular}

$* p<0.1, * * p<0.05, * * * p<0.01$, robust standard errors, absolute t-statistics in parenthesis 


\section{References}

Amuedo-Dorantes C, Pozo S (2011) New evidence on the role of remittances on healthcare expenditures by Mexican households. Rev Econ Househ 9:69-98

Angrist JD, Pischke J-S (2009) Mostly harmless econometrics: an empiricist's companion. New Jersey, Princeton University Press

Antman FM (2010) Adult child migration and the health of elderly parents left behind in Mexico. Amer Econ Rev 100(2):205-208

Antman FM (2016) How does international migration affect the health of elderly parents left behind? Evidence from Mexico. Working Paper. Department of Economics, University of Colorado at Boulder

Ao X, Jiang D, Zhao Z (2016) The impact of rural-urban migration on the health of the left-behind parents. Chin Econ Rev 37:126-139. Special issue on human capital, labor markets, and migration

Biao X (2007) How far are the left-behind left behind? A preliminary study in rural China. Polpul Space Place 13:179-191

Böhme MH, Persian R, Stöhr T (2015) Alone but better off? Adult child migration and health of elderly parents in Moldova. J Health Econ 39:211-227

Case A, Paxson C (2008) Height, health, and cognitive function at older ages. Amer Econ Rev 98(2):463467

Chen J (1998) Investment and support: an analysis on the cause and consequences of intergenerational exchange of urban citizens. Chinese Soc Sci 6:131-147. (in Chinese)

Chen X, Silverstein M (2000) Intergenerational social support and the psychological well-being of older parents in China. Res Aging 22(1):43-65

Cheng Y, Chi I, Boey K, Ko L, Chou K (2002) Self-rated economic condition and the health of elderly persons in Hong Kong. Soc Sci Med 55(8):1415-1424

Chyi H, Mao S (2012) The determinants of happiness of China's elderly population. J Happiness Stud 13(1):167-185

Clark AE, Oswald AJ (2002) A simple statistical method for measuring how life events affect happiness. Int J Epidemiol 31:1139-1144

Cohen S, Doyle WJ, Skomer DP, Fireman P, Gwaltney JM, Newson JP (1995) State and trait negative affect as predictors of subjective and objective symptoms of respiratory viral infections. J Pers Soc Psychol 68:159-169

Cong Z, Silverstein M (2008) Intergenerational support and depression among elders in rural China: do daughters-in-law matter? J Marriage Family 70:599-612

Croll E (1997) China's rural urban mobility (Part 1). Chin Rev 6:22-26

Davin D (1999) Internal migration in contemporary China. Palgrave Macmillan

Démurger S, Gurgand M, Li S, Yue X (2009) Migrants as second-class workers in urban China? A decomposition analysis. J Comp Econ 37(4):610-628

Du P (2003) Main financial resources of the elderly in China: reality and changes. Popul Res 6:37-43. (in Chinese)

Easterlin RA (2004) Explaining happiness. Proc Natl Acad Sci USA 100(19):11176-11183

Fan CC (2008) China in the move: migration, the stand and the household. Routledge, London

Farré L (2015) New evidence on the healthy immigrant effect. J Popul Econ 29(2):365-394

Frey BS, Stutzer A (2002) What can economists learn from happiness research? J Econ Lit 40(2):402-435

Galper DI, Trivedi MH, Barlow CE, Dunn AL, Kampert JB (2006) Inverse association between physical inactivity and mental health in men and women. Med Sci Sports Exer, 173-178

Gibson J, McKenzie D, Stillman S (2011) The impacts of international migration on remaining household members: omnibus results from a migration lottery program. Rev Econ Stat 93:1297-1318

Giles J, Mu R (2007) Elderly parent health and the migration decision of adult children: evidence from rural china. Demography 44(2):265-288

Giles J, Zhao C, Wang D (2010) Can China's rural elderly count on support from adult children? Implications of rural-to-urban migration. J Popul Ageing 3(3):183-204

Giles J, Wang D, Cai W (2011) The labor supply and retirement behavior of China's older workers and elderly in comparative perspective. Policy Research Working Paper 5853, The World Bank

Huang B, Lian Y, Li W (2015) How far is Chinese left-behind parents' health left behind? China Econ Rev 37:15-26

Jackson R, Howe N (2004) The graying of the middle kingdom: the demographics and economics of retirement policy in China. The Center for Strategic and International Studies, Washington D.C. 
Jasso G, Massey DS, Rosenzweig MR, Smith J (2004) Critical perspectives on racial and ethnic differences in health in late life. Washington D.C. National Academies Press, chap. Immigrant Health: Selectivity and Acculturation, pp 227-266

Knight J, Gunatilaka R (2010) Great expectations? The subjective well-being of rural-urban migrants in China. World Dev 38(1):113-124

Knight J, Gunatilaka R (2018) Rural-Urban migration and happiness in China. In: Helliwell, JF, Layard, R, Sachs JD (eds) World Happiness Report 2018

Knight J, Yueh L (2004) Job mobility of residents and migrants in urban China. J Comp Econ 32:637-660

Knight J, Song L, Huaibin J (1999) Chinese rural migrants in urban enterprises: three perspectives. J Develop Stud 35(3):73-104

Kuhn R (2004) Migration and health in Asia. Routledge, London. chap. A Longitudinal Analysis of Health and Mortality in a Migrant-sending Region of Bangladesh

Kuhn R, Everett B, Silvey R (2011) The effect of children's migration on elderly kin's health: a counterfactual approach. Demography 48:183-209

Lee Y-J, Xiao Z (1998) Children's support for elderly parents in urban and rural china: results from a national survey. J Cross Cult Gerontol 13(1):39-62

Lei X, Sun X, Strauss J, Zhang P, Zhao Y (2014) Depressive symptoms and SES among the mid-aged and elderly in China: evidence from the China health and retirement longitudinal study national baseline. Soc Sci Med 120:224-232

Li S, Démurger S (2013) Migration, remittances, and rural employment patterns: evidence from China. In: Giulietti C, Tatsiramos K, Zimmermann KF (eds) Labor market issues in China, vol 37, 8. Emerald Group Publishing Limited, pp 31-63

Liu Z (2005) Institution and inequality: the Hukou system in China. J Comp Econ 33:133-157

Liu P (2013) On the pension problems of rural communities. Publ Admin Law 6:63-72. (in Chinese)

Mckenzie D, Rapoport H (2007) Network effects and the dynamics of migration and inequality: theory and evidence from Mexico. J Dev Econ 84(1):1-24

Mosca I, Barrett A (2016) The impact of adult child emigration on the mental health of older parents. J Popul Econ, 1-33

National Bureau of Statistics of China (2012) Migration annual report., National Bureau of Statistics of China (http://www.stats.gov.cn/)

National Bureau of Statistics of China (2014) National Report on Migrant Worker Monitoring and Survey 2014. Tech. rep., National Bureau of Statistics of China, http://www.stats.gov.cn/

Oreopoulos P (2006) Estimating average and local average treatment effects of education when compulsory schooling laws really matter. Amer Econ Rev 96(1):152-175

Pang L, de Brauw A (2004) Scott work until you drop: the elderly of rural China. China J 52:73-96

Radloff LS (1977) The CES-D scale: a self-report depression scale for research in the general population. Appl Psychol Meas 1(3):385-401

Riosmena F, González-González C, Wong R (2012) Recent returns from the United States: health, wellbeing and vulnerability of older adults. Coyuntura Demográfica 23:1019-1026

Rozelle S, Guo L, Shen M, Hughart A, Giles J (1999) Leaving China's farms: survey results of new paths and remaining hurdles to rural migration. China Quart 158:367-393

Rubalcava L, Teruel GM, Thomas D, Goldman N (2008) The healthy migrant effect: new findings from the Mexican family life survey. Am J Public Health 98(1):78-84

Silverstein M, Gans D, Yang FM (2006) Intergenerational support to aging parents: the role of norms and needs. J Fam Issues 27:1068-1084

Stevens AH, Miller DL, Page ME, Filipski M (2015) The best of times, the worst of times: understanding pro-cyclical mortality. Amer Econ J Econ Polic 7(4):279-311

Stock JH, Yogo M (2002) Testing for weak instruments in linear IV regression. NBER Technical Working Papers 0284. National Bureau of Economic Research, Inc

Sun R (2002) Old age support in contemporary urban China from both parents' and children's perspectives. Res Aging 24(3):337-359

Vanwey LK (2004) Altruistic and contractual remittances between male and female migrants and households in rural Thailand. Demography 41:739-756

Veenhoven R (2008) Healthy happiness: effects of happiness on physical health and the consequences for preventive health care. J Happiness Stud 9:449-469

Wang D (2005) China's urban and rural old age security system: challenges and options. China World Econ 14(1):102-116 
Yao Y (2011) Chinese family support study. Chinese Population Press, Beijing

Zhang Y, Hu T (2014) Review and reflections of elderly long-term care financing mode research. Soc Secur Stud 6:96-104. (in Chinese)

Zhang W, Li S (2004) An analysis of the effects of labour emigration on family support for the elderly in rural China. Chin Soft Sci 8:34-39. (in Chinese)

Zhang Y, Li Y (2015) Literature review on the needs and determination factors of rural elder household caring. China Soc Welfare 8:53-57. (in Chinese)

Zhang W, Li S, Feldman MW (2005) Gender differences in activity of daily living of the elderly in rural china: evidence from Chaohu. J Women Ageing 17(3):73-89

Zhao Y (1999) Labor migration and earnings differences: the case of rural China. Econ Dev Cult Chang 47(4):767-782

Zheng Z, Huang J (2014) The function of rural community elderly association in new rural construction: a case study of Fujiang Q community. J Agri 4(12):107-109. (in Chinese)

Zhuo Y, Liang Z (2006) Migration and the well-being of the elderly in rural China. In: Paper presented at annual meetings of the population association of America. California

Zuo D, Li S (2011) The impact of labour migration on healthy well-being of elderly left behind in rural China: studies based on surveys in inflow and outflow places. J Public Manag 8(2):93-127

Zweig D (1997) Freeing China's farmers: rural restructuring in the reform era. M.E. Sharpe, New York 